\title{
Preserving the pulmonary valve during early repair of tetralogy of Fallot: Anatomic substrates and surgical strategies
}

\author{
Vladimiro L. Vida, MD, PhD, ${ }^{a}$ Annalisa Angelini, MD, ${ }^{\mathrm{b}}$ Alvise Guariento, MD, ${ }^{\mathrm{a}, \mathrm{c}}$ Carla Frescura, MD, \\ Marni Fedrigo, MD, ${ }^{\mathrm{b}}$ Massimo Padalino, MD, PhD, ${ }^{\mathrm{a}}$ Stephen P. Sanders, MD, ${ }^{\mathrm{c}}$ Gaetano Thiene, MD, ${ }^{\mathrm{b}}$ and \\ Giovanni Stellin, $\mathrm{MD}^{\mathrm{a}}$
}

Objective: To describe the anatomy of the PV in tetralogy of Fallot (TOF) and to define the influence of PV anatomy on the development of surgical techniques for PV preservation during early repair.

\begin{abstract}
Methods: The PV was evaluated in 79 anatomic specimens of patients with TOF who had not undergone surgery for repair, and in 82 patients who underwent early TOF repair at our institution. New surgical techniques for PV preservation during early repair are described.
\end{abstract}

Results: The PV in TOF was predominantly bicuspid $(n=118$ of $160 ; 73.7 \%)$, less frequently tricuspid $(n=28$ of $160 ; 17.5 \%)$, and seldom unicuspid $(\mathrm{n}=14$ of $160 ; 8.8 \%)$. In 82 cases $(51.3 \%)$, the PV cusps were normal; in 78 cases $(48.7 \%)$, they were thickened and dysplastic. Preservation of the PV was possible in 46 of $82(56 \%)$ consecutive patients during TOF repair in our more recent experience, either using balloon dilation alone ( 18 of $46 ; 39 \%$ ) or in association with other PV plasty procedures (28 of 46; 61\%). Most bicuspid and tricuspid valves were salvageable, but unicuspid valves were not suitable. After a median follow-up time of 2.8 years (range, 0.5-6.8 years), the degree of PV regurgitation continued to be zero or mild in 40 patients $(86 \%)$, and moderate in $6(14 \%)$.

Conclusions: The majority of patients with TOF $(>90 \%)$ have a bicuspid or tricuspid PV, which is the most favorable surgical anatomy for preserving the PV, independent of the degree of leaflet dysplasia. The recent introduction of more-complex PV plasty techniques, such as delamination plasty, allowed us to further extend the applicability of PV-preservation techniques. (J Thorac Cardiovasc Surg 2015;149:1358-63)

See related commentary page 1364 .

Supplemental material is available online.

Continuous improvements in surgical technique and postoperative management have made repair of tetralogy of Fallot (TOF) feasible in early infancy, with low risk. ${ }^{1-5}$ Despite awareness of the late consequences of pulmonary valve $(\mathrm{PV})$ regurgitation, ${ }^{6-8}$ transannular patching of the right ventricular outflow tract (RVOT) remains the most prevalent technique for TOF repair. ${ }^{1,2}$ Techniques have been developed to avoid a large ventriculotomy during

From the Pediatric and Congenital Cardiac Surgery Unit, ${ }^{a}$ Cardiovascular Pathology Unit, ${ }^{\mathrm{b}}$ Department of Thoracic, Cardiac and Vascular Sciences, University of Padua, Padua, Italy; and Cardiac Registry, ${ }^{\mathrm{c}}$ Departments of Cardiology, Pathology, and Cardiac Surgery, Boston Children's Hospital, Boston, Mass.

Disclosures: Authors have nothing to disclose with regard to commercial support.

Received for publication Nov 5, 2014; revisions received Dec 30, 2014; accepted for publication Jan 17, 2015.

Address for reprints: Giovanni Stellin, MD, Pediatric and Congenital Cardiac Surgery Unit, Department of Thoracic, Cardiac and Vascular Sciences, University of Padua, Via Giustiniani, 2- 35100 Padua, Italy (E-mail: giovanni.stellin@unipd.it).

$0022-5223 / \$ 36.00$

Copyright (c) 2015 by The American Association for Thoracic Surgery

http://dx.doi.org/10.1016/j.jtcvs.2015.01.030
TOF repair, and recently, interest has shifted to preserving the integrity of the PV annulus, thus avoiding PV regurgitation.-16 We undertook an analysis of the anatomy of the PV in TOF, to support efforts to develop new surgical PV-preservation techniques.

\section{METHODS}

For the review of medical records, and the use of computerized hospital data, which was approved by the Clinical Investigation Committee of the University Hospital of Padua, the procedures followed were in accordance with the institutional guidelines for retrospective record review and protection of patient confidentiality. Patients were not identified, and the chairperson of the Ethics Committee gave consent for the patients' data to be submitted for publication.

We enrolled all patients who underwent TOF repair with intraoperative PV preservation at our institution since June 2007. Patients were excluded if they: had mild forms of TOF and did not require surgical manipulation of the PV; had TOF with severe PV stenosis and diminutive pulmonary artery branches with aorto-pulmonary collaterals and were treated by right ventricle-pulmonary artery conduit interposition; or had TOF with absent PV or double-outlet right ventricle. Patients who were followed for $<6$ months after surgery were excluded from the analysis $(n=4$ patients who underwent PV preservation). In addition, 2 patients were excluded who required a reoperation for residual RVOT obstruction after the initial repair (1, the first in our experience, underwent an initial PV preservation, and the other underwent surgery for a transannular patch).

The PV-preservation technique by intraoperative balloon dilation during early repair of TOF has been previously described. ${ }^{10,11}$ When the PV effective orifice is particularly narrow (z-score $<-3$ ), additional surgical procedures on the PV are usually required after dilatation, to achieve valve competence. Usually the repair and resuspension of the PV leaflet 


\section{Abbreviations and Acronyms \\ $\mathrm{PV}=$ pulmonary valve \\ RVOT $=$ right ventricular outflow tract \\ TOF $=$ tetralogy of Fallot}

is sufficient (simple PV plasty); however, in more-severe cases, in which the balloon splays the PV commissures apart, causing the leaflets to become insufficient to cover the new PV annular area, more-complex PV plasty procedures, including PV cusp delamination, may be required.

In these patients, thickened PV cusps are initially thinned by shaving; the coaptation area is extended by carefully delaminating the base of each PV cusp at the hinge point, with a fine scalpel, extending down into the right ventricular myocardium when necessary. Subsequently, the extended cusps are resuspended, creating new PV commissures. Occasionally, PV cusps are extended using small triangles of prosthetic (biologic) patch material, before they are resuspended (Figure 1, $A-G$ ). (An excised bovine heart model was used to better understand the delamination plasty technique [Figures E1 and E2].)

Goals of the intraoperative PV balloon dilation are to achieve: (1) an annular PV Z-score of zero; and (2) a half-systemic right ventricular pressure. ${ }^{10,11}$ Transesophageal and transthoracic echocardiography (iE33 xMATRIX Echocardiography System; Philips Medical System, Andover, Mass) was used to monitor immediate surgical results, and results at hospital discharge and during outpatient follow-up. Pulmonary regurgitation was quantified as: (1) zero to mild; (2) moderate; and (3) severe. ${ }^{17,18}$ The primary outcome of this study was to assess the effectiveness of the PV-preservation strategies during early TOF repair by focusing on shortterm PV function and the influence of PV anatomy on the development of these surgical techniques.

\section{Anatomic Evaluation}

The heart specimens used in this project were collected during the middle portion of the 20th century. In each case, the family provided written consent for the specimen to be maintained in the pathology laboratory and used for research and teaching in accordance with the hospital policy in place at the time of collection. We reviewed 79 anatomic specimens of uncorrected TOF (50 from The Cardiac Registry, Boston Children's Hospital, Boston, Mass, and 29 from the Regional Registry of Cardiovascular and Cerebro-Vascular Pathology of the University of Padua, Padua, Italy). We excluded specimens that had undergone surgical correction or isolated RVOT enlargement (Brock procedure). In addition, we excluded variants of TOF, including TOF with PV atresia, TOF with absent PV, and TOF with atrioventricular septal defect. Specimens of patients who had undergone palliation with a systemic-to-pulmonary shunt were included.

We analyzed the PV morphology, including the number of leaflets and commissures composing the valve, the presence of leaflet thickening and dysplasia, and the presence of leaflet or annular calcification. Similar inspection of the PV was performed in 82 recent, consecutive patients who underwent early transatrial TOF repair. In addition, in patients in whom the PV was preserved during TOF repair $(\mathrm{n}=46)$, measurements were made, and their associated Z-scores calculated, ${ }^{19,20}$ of the effective PV opening, in millimeters (at the valvular level, before any surgical procedure was done); the true PV annulus diameter (after PV commissurotomy was done); and the final PV diameter (after balloon dilation).

\section{Statistical Analysis}

Categoric variables are shown as absolute frequency and percentage. Quantitative variables were summarized as median and range. If quantitative variables were not normally distributed (assessed by the

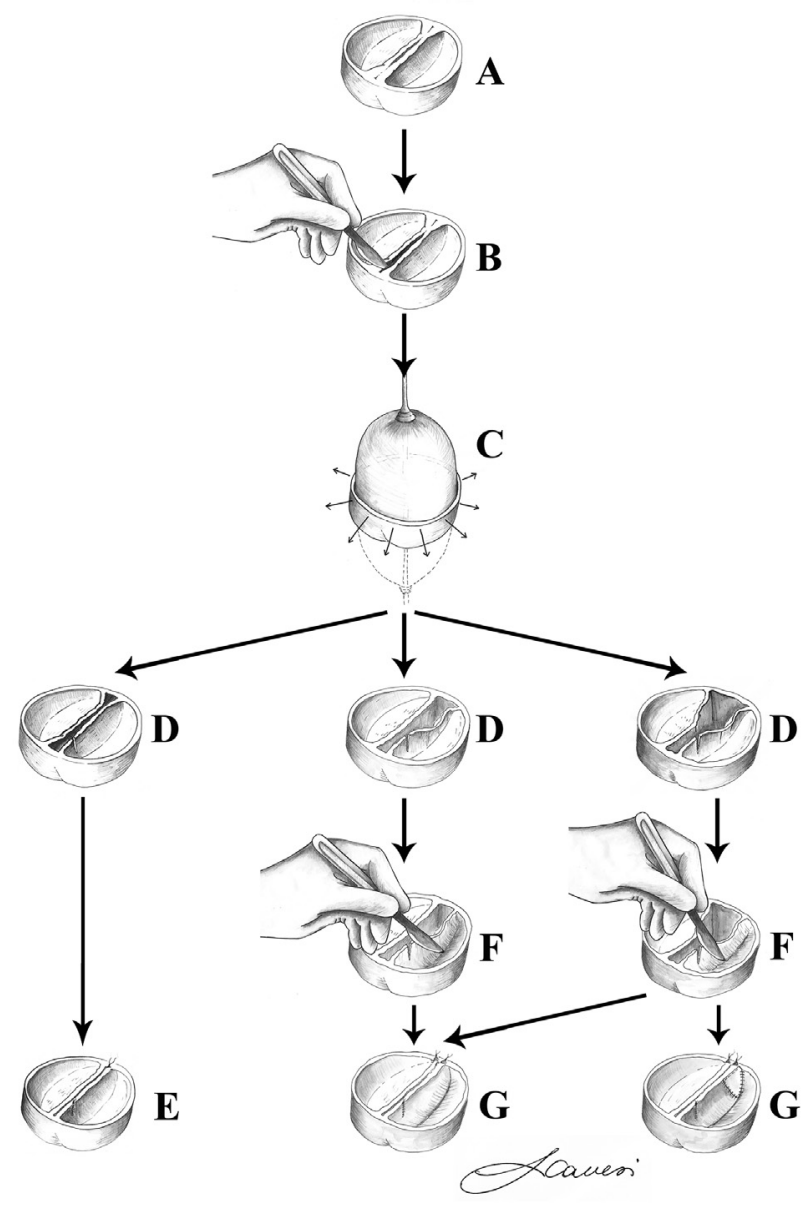

FIGURE 1. The drawing shows the various types of PV plasty procedures that can be performed in addition to PV balloon dilation: (A) dysplastic PV with commissure fusion (effective PV opening); (B) PV commissurotomy (true initial PV annulus diameter); (C) PV balloon dilation and (D) final PV annulus diameter; (E) simple additional PV plasty (including PV leaflet repair and resuspension); (F-G) complex additional PV plasty, including PV leaflet delamination $(F)$ and patch augmentation when needed and resuspension $(G)$.

Shapiro-Wilk normality test), comparison among groups was carried out using Kruskal-Wallis analysis of variance. Categoric variables were compared using the $\chi^{2}$ test or the Fisher exact test, as appropriate. All reported $P$ values are 2 -sided. Statistical analysis was performed using SAS software (SAS Institute, Inc, Cary, NC).

\section{RESULTS}

Intraoperative Measurements and Operative Results

Since 2007, we were able to preserve the PV in 46 of the 82 consecutive patients $(56 \%)$ who underwent repair of TOF (Figure 2), including 0 of 4 unicuspid valves $(0 \%)$; 37 of 67 bicuspid valves (55\%); and 9 of 10 tricuspid valves $(90 \%)$ (Figure 3). The PV was dysplastic in 20 patients (43\%) - 4 with a tricuspid PV, and 16 with a bicuspid PV. The median, preoperative, 2-dimensional, echocardiographic PV Z-score in these 46 patients was -2.89 (range, -1.19 to -4.7 ) and was significantly lower in patients with 


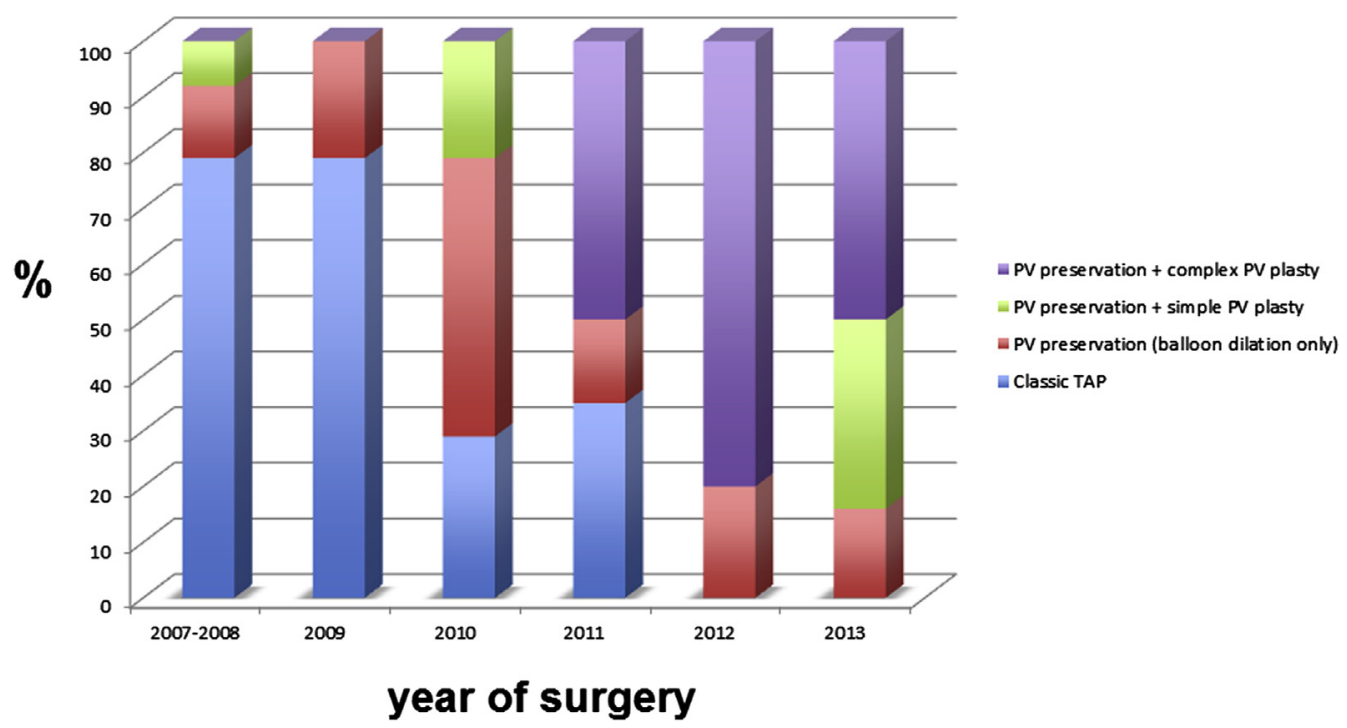

FIGURE 2. Histogram showing the percentage of patients who underwent PV preservation during tetralogy of Fallot repair, since 2007, in our institution (including PV balloon dilation only, and PV balloon dilation in association with simple and complex PV plasty). $P V$, Pulmonary valve; TAP, transannular patch.

a bicuspid PV, compared with patients with a tricuspid PV $(P=.009$; Figure $3, A)$. Median age at surgery was 3.4 months (range, 1.1-43 months), and their median body weight was $5.8 \mathrm{~kg}$ (range, $3.2-10.1 \mathrm{~kg}$ ). Only 1 patient, coming from another institution, had previously undergone a palliative procedure (a stent was placed in the patent ductus arteriosus for severe arterial oxygen desaturation).

The median effective PV orifice (measured with a Hegar dilator [Medline Industries Inc, Mundelein, Ill] before any surgical procedure of the $\mathrm{PV}$ ) was $5 \mathrm{~mm}$ (range, 3-8 $\mathrm{mm}$ ); this value increased to a median value of $7 \mathrm{~mm}$ (range, 6$9 \mathrm{~mm}$ ) after PV commissurotomy (true PV annulus diameter). The subsequent intraoperative balloon dilation produced a further median increase of the PV diameter of $2 \mathrm{~mm}$ (range, 1-4 mm), reaching in all patients the normal value of the PV diameter calculated for each patient's body surface area. Twenty-eight patients $(61 \%)$ underwent an additional plasty procedure on the PV, including: (1) resuspension of the PV cusps ( $\mathrm{n}=8$, simple PV plasty); (2) PV cusp delamination, cusp patch augmentation when needed, and resuspension $(\mathrm{n}=20$, complex PV plasty). The median, preoperative, 2-dimensional echocardiographic PV Z-score was significantly lower in patients who required an additional PV plasty $(P=.04$; Figure 3, $B)$.

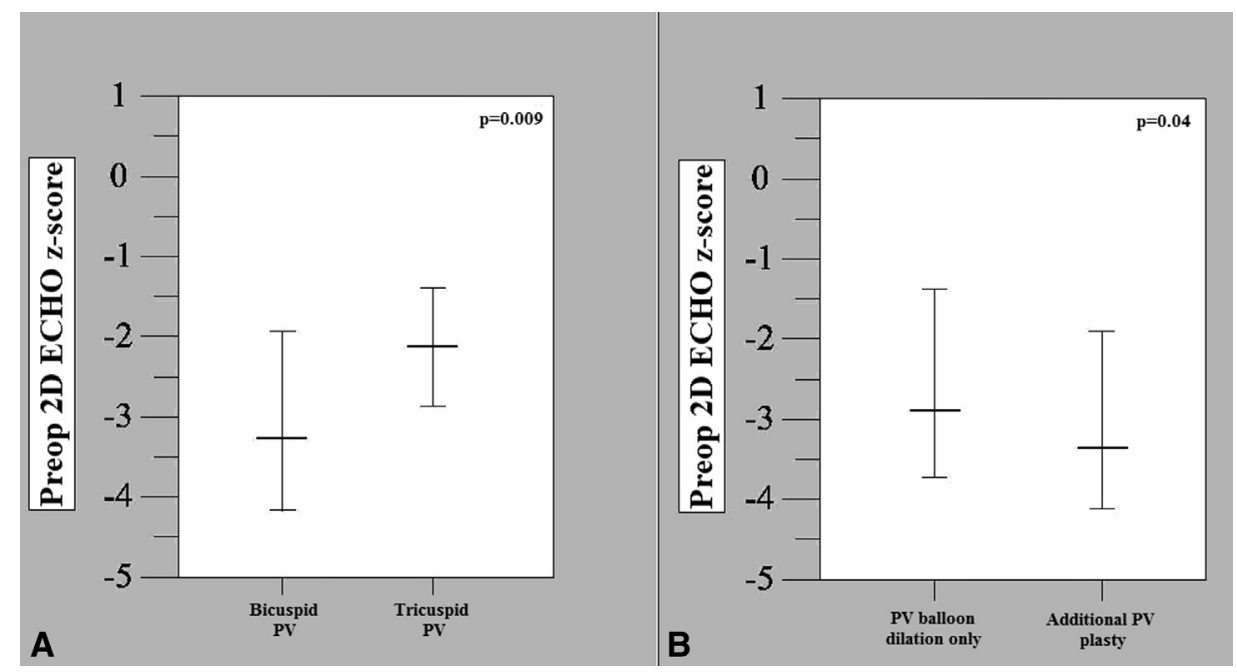

FIGURE 3. The box-plot shows the difference between the preoperative, 2-dimensional, echocardiographic PV Z-score in (A) patients who had a bicuspid $\mathrm{PV}$, compared with patients with a tricuspid PV $(P=.009)$, and $(\mathrm{B})$ patients who underwent a PV balloon dilation only, or an additional PV plasty procedure $(P=.04)$. Preop, Preoperative; $2 D$, 2-dimensional; $E C H O$, echocardiographic; $P V$, pulmonary valve. 
TABLE 1. Two-dimensional echocardiographic data at discharge and follow-up

\begin{tabular}{|c|c|c|}
\hline & $\begin{array}{l}\text { At discharge } \\
(n=46)\end{array}$ & $\begin{array}{l}\text { At follow-up } \\
(n=46)\end{array}$ \\
\hline $\begin{array}{l}\text { Median RVOT gradient } \\
\quad(\mathrm{mm} \mathrm{Hg} \text { [range] })\end{array}$ & $27(15-45)$ & $24(7-45)$ \\
\hline \multicolumn{3}{|l|}{ RVOT gradient grade (n [\%]) } \\
\hline - Grade $1(<20 \mathrm{~mm} \mathrm{Hg})$ & $2(4.4)$ & $1(2.5)$ \\
\hline - Grade $2(20-40 \mathrm{~mm} \mathrm{Hg})$ & $40(87)$ & $42(91)$ \\
\hline - Grade 3 (>40 mm Hg) & $4(8.8)$ & $3(6.5)$ \\
\hline PV Z-score, n (range) & $-0.2(-1.2$ to 0.5$)$ & $-0.1(-0.9$ to 0.7$)$ \\
\hline \multicolumn{3}{|l|}{$\begin{array}{l}\text { Degree of PV regurgitation } \\
\quad(\mathrm{n}[\%])\end{array}$} \\
\hline - Grade 1 (zero to mild) & $41(89)$ & $40(86)$ \\
\hline - Grade 2 (moderate) & $4(11)$ & $6(14)$ \\
\hline - Grade 3 (severe) & - & - \\
\hline
\end{tabular}

At the cardiopulmonary bypass discontinuation, the right ventricular pressure, measured by direct puncture, was less than one third of the systemic pressure in 12 patients $(26 \%)$; less than one half of the systemic pressure in $30(65 \%)$; and less than three quarters of the systemic pressure in $4(9 \%)$. At discharge, the median RVOT gradient was $27 \mathrm{~mm} \mathrm{Hg}$ (range, 15-45 $\mathrm{mm} \mathrm{Hg}$ ), and the PV was competent or mildly regurgitant in 41 of 46 patients $(89 \%)$; in 4 patients, the regurgitation of the PV was judged to be mild to moderate. Echocardiographic data at discharge are summarized in Table 1.

After a median follow-up time of 2.8 years (range, 0.5-6.8 years), the degree of PV regurgitation continued to be either zero or mild in 40 patients $(86 \%)$, and moderate in 6 patients $(14 \%)$. The median RVOT gradient was $24 \mathrm{~mm}$ $\mathrm{Hg}$ (range, 7-45 $\mathrm{mm} \mathrm{Hg}$ ) and did not differ significantly between patients who underwent a simple versus a complex PV-preservation plasty (Table 1). In the subset of patients who underwent a more recent complex PV plasty, the median follow-up time was 2 years (range, 0.5-3.8 years), with a similar degree of PV regurgitation compared with patients who underwent balloon dilation only or a balloon dilation combined with a simple PV plasty (the degree of $\mathrm{PV}$ regurgitation in the short term, in patients who underwent balloon dilation combined with a complex PV plasty, was zero or mild in 18 patients [90\%], and moderate in 2 patients $[10 \%])$.

\section{Pulmonary Valve Anatomic Characteristics in Tetralogy of Fallot}

These characteristics describe 154 samples, including 79 heart specimens and 75 intraoperative measurements. The PV was predominantly bicuspid ( $\mathrm{n}=113 ; 74 \%$ ), less frequently tricuspid $(\mathrm{n}=27 ; 17 \%)$, and seldom unicuspid $(\mathrm{n}=14 ; 9 \%)$. In the majority of cases $(\mathrm{n}=79 ; 51 \%)$, the PV cusps were normal. Dysplasia of the PV cusps with fibrotic thickening (Figure 4), especially at the free edge, was present in the remaining 75 cases $(49 \%)$. Dysplasia of the PV cusps was present in 11 of 14 patients with a unicuspid valve (79\%), in 57 of 113 with a bicuspid valve $(51 \%)$, and in 8 of 27 with a tricuspid valve $(29 \%)$ $(P=.007)($ Figure 5)
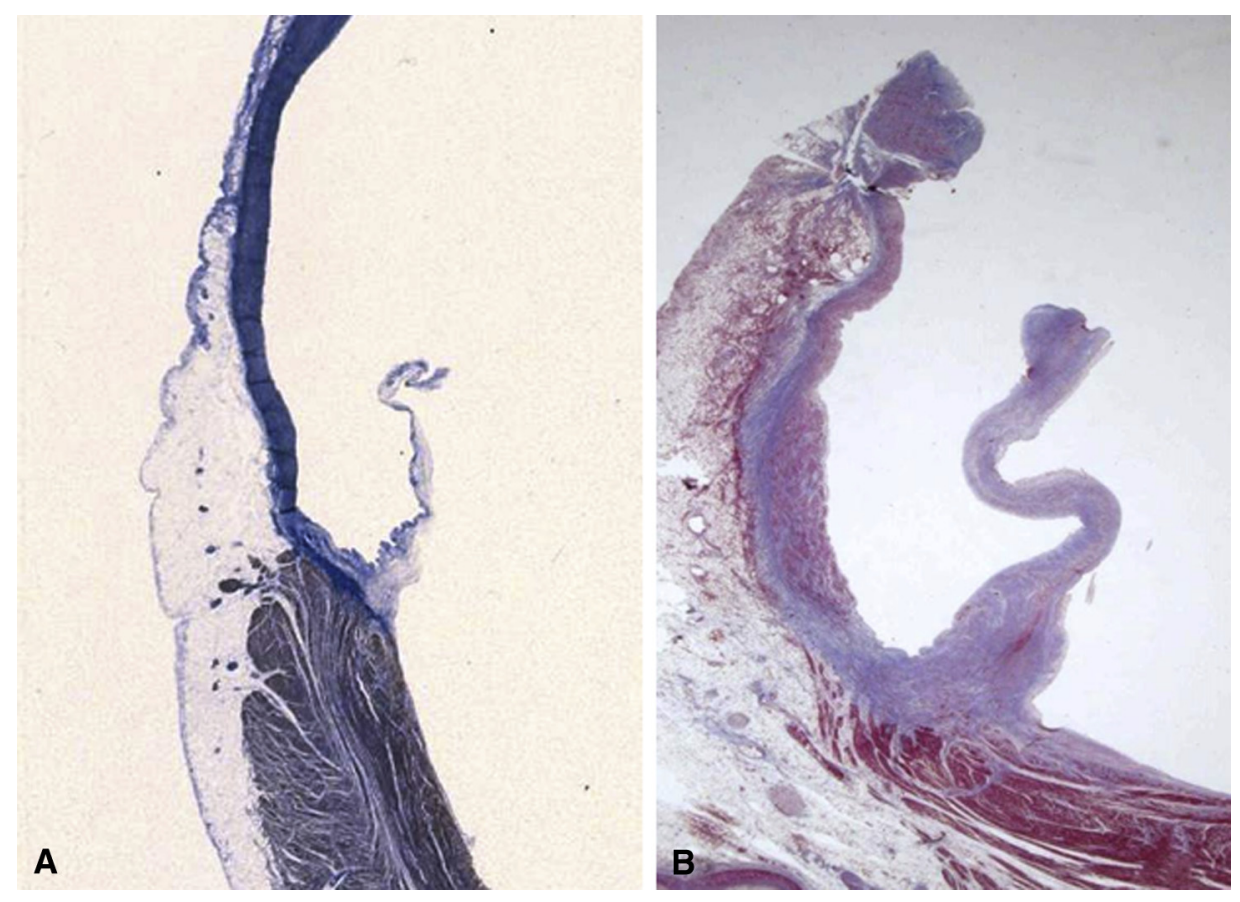

FIGURE 4. Histologic examination of (A) a normal PV, and (B) a dysplastic PV in TOF: At histology, the dysplastic PV in TOF shows enlargement of spongiosa, fragmentation of fibrosa, and fibrotic thickening of the free edge (magnification $\times 1$, elastic fiber Van Gieson staining). 


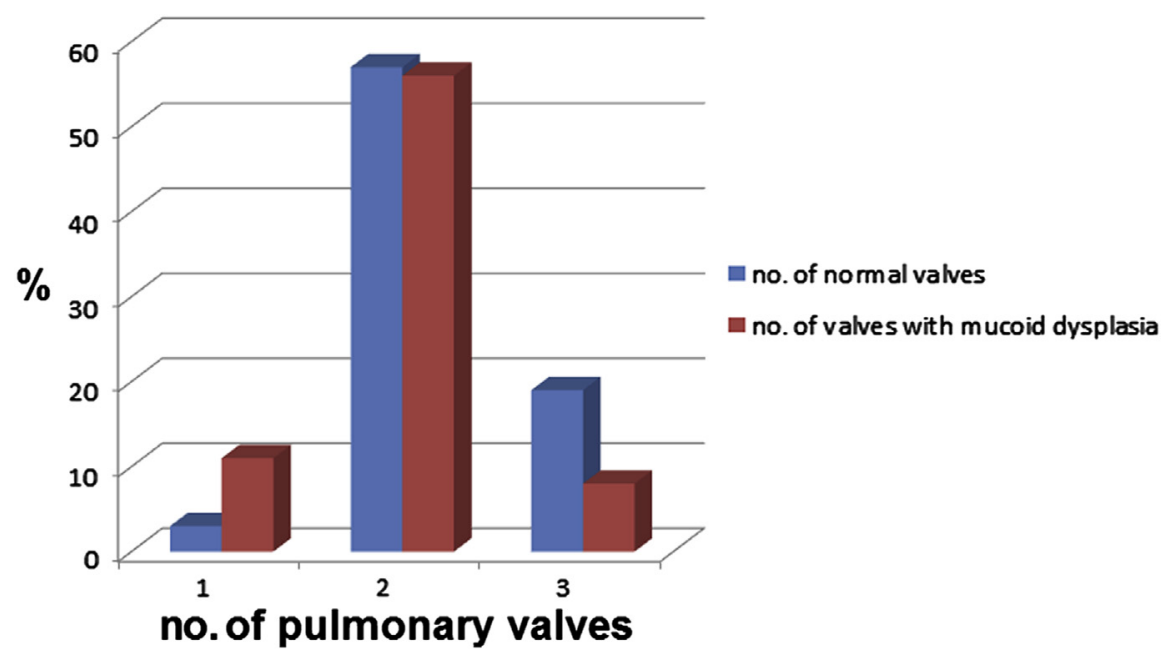

FIGURE 5. The histogram shows the relationship between the number of pulmonary valve cusps and the presence of mucoid dysplasia in TOF (including 79 anatomic specimens of patients who had not undergone operation, and 75 patients who underwent early TOF repair in our institution). no., Number.

\section{DISCUSSION}

Continuous improvements in surgical techniques have made repair of tetralogy of Fallot feasible in early infancy, with low risk. ${ }^{4,16,21-23}$ Based on long-term outcomes of conventional TOF repair, many centers ${ }^{9-17}$ have developed techniques designed to preserve PV function and thus limit or eliminate the long-term consequences of chronic $\mathrm{PV}$ regurgitation on ventricular function. ${ }^{7,24-28}$ During the past 7 years, with the aim of preserving PV function, we embarked on a new surgical approach for TOF repair that combines our standard, early, transatrial, transpulmonary TOF repair with intraoperative PV balloon dilation..$^{10-12}$ Furthermore, in more-severe cases, additional surgical procedures on the PV, including delamination plasty, were adopted to promote valve competence.

Our previous results show that the PV annulus and function can be preserved in selected patients undergoing early surgical repair of TOF, by combining a transatrialtranspulmonary with a subpulmonary muscular resection, without interfering with the ventriculo-arterial junction. Our results allowed us to achieve significantly better PV competence and right ventricular function in the midterm, compared with classic TOF repair with the utilization of a transannular patch. ${ }^{11}$ In this study, we have shown that the vast majority of PVs in TOF are bicuspid or tricuspid $(>90 \%)$, and this anatomy is the most favorable surgically for applying PV-preservation procedures, regardless of the degree of leaflet dysplasia. On the contrary, a unicuspid $\mathrm{PV}$ is almost impossible to enlarge adequately at the single commissure, particularly when it is associated with a very hypoplastic PV annulus.

After our initial results, ${ }^{10,11}$ we expanded the applicability of this technique to patients with a smaller PV annulus (Z-score $\leq-3$ ), by the addition of complex surgical plasty of the PV, in recent studies. The overall PV-preservation rate was $56 \%$ and ranged from $21 \%$ (during the initial 2 years of our experience) to $100 \%$ (during the last 2 years of our experience). The more-aggressive use of complex PV plasty techniques, which have been applied in a progressively increasing percentage of patients since 2011 (up to $80 \%$ during the past few years; Figure 2), allows PV preservation, even in patients with very severe $\mathrm{PV}$ annular hypoplasia (PV Z-score $<-4$ ). The PV, in these severe cases, is almost unable to cover the entire RVOT area, and it is disrupted after PV balloon dilation. The recent introduction of delamination PV plasty allows the extension of the cusp's coaptation surface, which is important for achieving acceptable PV competence. In more-severe cases, small biologic patches were used to extend the delaminated leaflet, helping them cover the whole PV annular area and avoiding stenosis at the PV level, which might otherwise occur as a result of their resuspension.

During the initial use of the delamination plasty procedure, we were concerned about the possibility of hematoma in the outflow myocardium or tearing or other failure of the delaminated valve leaflets. However, after a median time of 2 years, we have not seen any sign of PV dysfunction, right ventricular muscle hematoma, or other anomaly indicating failure of the PV plasty procedures. We believe that the low pressure in the pulmonary circuit is key to the success of this $\mathrm{PV}$ plasty technique, allowing us to be very aggressive in PV cusp extension.

This study has limitations. First, the design is a retrospective data examination. Second, the treated population with TOF is still quite young and has had only short follow-up times, especially in cases that required a complex PV plasty after balloon dilation. Consequently, we do not know the long-term outcome of this technique. Finally, we do not 
have human autopsy data in patients who underwent the valve-preservation techniques described, so we have not evaluated anatomic appearance after this procedure.

In conclusion, the majority of patients with TOF have a bicuspid or tricuspid PV, which is the most favorable surgical anatomy for preserving the $\mathrm{PV}$, independent of the presence or degree of leaflet dysplasia. We believe that the preservation of the PV annulus and PV function during early repair of TOF, by combining intraoperative PV balloon dilation and additional surgical procedures, can be extended to the majority of patients with classic TOF. The recent introduction of more-complex PV plasty techniques, including delamination plasty, allowed us to further extend the applicability of PV-preservation techniques.

The authors thank Dr Rubina Canesi for her drawings.

\section{References}

1. Al Habib HF, Jacobs JP, Mavroudis C, Tchervenkov CI, O'Brien SM, Mohammadi S, et al. Contemporary patterns of management of tetralogy of Fallot: data from the Society of Thoracic Surgeons Database. Ann Thorac Surg. 2010;90:813-9.

2. Sarris GE, Comas JV, Tobota Z, Maruszewski B. Results of reparative surgery for tetralogy of Fallot: data from the European Association for Cardio-Thoracic Surgery Congenital Database. Eur J Cardiothorac Surg. 2012;42:766-74.

3. Jonas RA. Early primary repair of tetralogy of Fallot. Semin Thorac Cardiovasc Surg Pediatr Card Surg Annu. 2009;2:39-47.

4. Bové T, François K, Van De Kerckhove K, Panzer J, De Groote K, De Wolf D, et al. Assessment of a right-ventricular infundibulum-sparing approach in transatrial-transpulmonary repair of tetralogy of Fallot. Eur J Cardiothorac Surg. 2012;41:126-33.

5. Barron D. Tetralogy of Fallot: controversies in early management. World J Pediatr Congenital Heart Surg. 2013;4:186-91.

6. Puranik R, Tsang V, Lurz P, Muthurangu V, Offen S, Frigiola A, et al. Long-term importance of right ventricular outflow patch function in patients with pulmonary regurgitation. J Thorac Cardiovasc Surg. 2012;143:1103-7.

7. Eyskens B, Brown SC, Claus P, Dymarkowski S, Gewillig M, Bogaert J, et al. The influence of pulmonary regurgitation on regional right ventricular function in children after surgical repair of tetralogy of Fallot. Eur $J$ Echocardiogr. 2010;11:341-5.

8. van den Berg J, Hop WC, Strengers JL, de Jongste JC, van Osch-Gevers L, Meijboom FJ, et al. Clinical condition at mid-to-late follow-up after transatrial-transpulmonary repair of tetralogy of Fallot. J Thorac Cardiovasc Surg. 2007; 133:470-7.

9. Robinson JD, Rathod RH, Brown DW, Del Nido PJ, Lock JE, McElhinney DB, et al. The evolving role of intraoperative balloon pulmonary valvuloplasty in valve-sparing repair of tetralogy of Fallot. J Thorac Cardiovasc Surg. 2011; 142:1367-73.

10. Vida VL, Padalino MA, Maschietto N, Biffanti R, Anderson RH, Milanesi O, et al. The balloon dilation of the pulmonary valve during early repair of tetralogy of Fallot. Catheter Cardiovasc Interv. 2012;80:915-21.

11. Vida VL, Guariento A, Castaldi B, Sambugaro M, Padalino MA, Milanesi O, et al. Evolving strategies for preserving the pulmonary valve during early repair of tetralogy of Fallot: mid-term results. J Thorac Cardiovasc Surg. 2014;147: 687-94; discussion 694-6.

12. Hoashi T, Kagisaki K, Meng Y, Sakaguchi H, Kurosaki K, Shiraishi I, et al. Long-term outcomes after definitive repair for tetralogy of Fallot with preservation of the pulmonary valve annulus. J Thorac Cardiovasc Surg. 2014; 148:802-8; discussion 808-9.

13. Bacha E. Valve-sparing options in tetralogy of Fallot surgery. Semin Thorac Cardiovasc Surg Pediatr Card Surg Annu. 2012;15:24-6.

14. Hua Z, Li S, Wang L, Hu S, Wang D. A new pulmonary valve cusp plasty technique markedly decreases transannular patch rate and improves midterm outcomes of tetralogy of Fallot repair. Eur J Cardiothorac Surg. 2011;40:1221-6.

15. Sasson L, Houri S, Raucher Sternfeld AR, Cohen I, Lenczner O, Bove EL, et al Right ventricular outflow tract strategies for repair of tetralogy of Fallot: effect of monocusp valve reconstruction. Eur J Cardiothorac Surg. 2013;43:743-51.

16. Stewart RD, Backer CL, Young L, Mavroudis C. Tetralogy of Fallot: results of a pulmonary valve-sparing strategy. Ann Thorac Surg. 2005;80:1431-8.

17. Pettersen MD, Du W, Skeens ME, Humes RAJ. Regression equations for calculation of z scores of cardiac structures in a large cohort of healthy infants, children, and adolescents: an echocardiographic study. Am Soc Echocardiogr. 2008;21:922-34.

18. Puchalski MD, Askovich B, Sower CT, Williams RV, Minich LL, Tani LY Pulmonary regurgitation: determining severity by echocardiography and magnetic resonance imaging. Congenit Heart Dis. 2008;3:168-75.

19. Grothoff M, Spors B, Abdul-Khaliq H, Gutberlet M. Evaluation of postoperative pulmonary regurgitation after surgical repair of tetralogy of Fallot: comparison between Doppler echocardiography and MR velocity mapping. Pediatr Radiol. 2008;38:186-91.

20. Parameter(z). Echo Z-score calculators. Available at: http://parameterz.blogspot com/2008/09/cardiac-valve-Z-scores.htm. Accessed December 22, 2014.

21. Stellin G, Milanesi O, Rubino M, Michielon G, Bianco R, Moreolo GS, et al Repair of tetralogy of Fallot in the first six months of life: transatrial versus transventricular approach. Ann Thorac Surg. 1995;60(6 Suppl):S588-91.

22. Sfyridis PG, Kirvassilis GV, Papagiannis JK, Avramidis DP, Ieromonachos CG, Zavaropoulos PN, et al. Preservation of right ventricular structure and function following transatrial-transpulmonary repair of tetralogy of Fallot. Eur J Cardiothorac Surg. 2013;43:336-42.

23. Winn KJ, Hutchins GM. The pathogenesis of tetralogy of Fallot. Am J Pathol 1973;73:157-72

24. Ferraz Cavalcanti PE, Sá MP, Santos CA, Esmeraldo IM, de Escobar RR, de Menezes AM, et al. Pulmonary valve replacement after operative repair of tetralogy of Fallot. Meta-analysis and meta-regression of 3118 patients from 48 studies. J Am Coll Cardiol. 2013;62:2227-43.

25. Frigiola A, Tsang V, Bull C, Coats L, Khambadkone S, Derrick G, et al Biventricular response after pulmonary valve replacement for right ventricular outflow tract dysfunction: Is age a predictor of outcome? Circulation. 2008; 118(14 Suppl):S182-90.

26. Buckberg G, Hoffman JI. Effect of right ventricular free wall ventriculotomy on right ventricular function: Is that the correct question? J Thorac Cardiovasc Surg. 2014;148:752-3

27. Lee C, Lee CH, Kwak JG, Kim SH, Shim WS, Lee SY, et al. Factors associated with right ventricular dilatation and dysfunction in patients with chronic pulmonary regurgitation after repair of tetralogy of Fallot: analysis of magnetic resonance imaging data from 218 patients. J Thorac Cardiovasc Surg. 2014;148: 2589-96.

28. Lee C, Lee CH, Kwak JG, Kim SH, Shim WS, Lee SY, et al. Does limited right ventriculotomy prevent right ventricular dilatation and dysfunction in patients who undergo transannular repair of tetralogy of Fallot? Matched comparison of magnetic resonance imaging parameters with conventional right ventriculotomy long-term after repair. J Thorac Cardiovasc Surg. 2014;147: 889-95. 


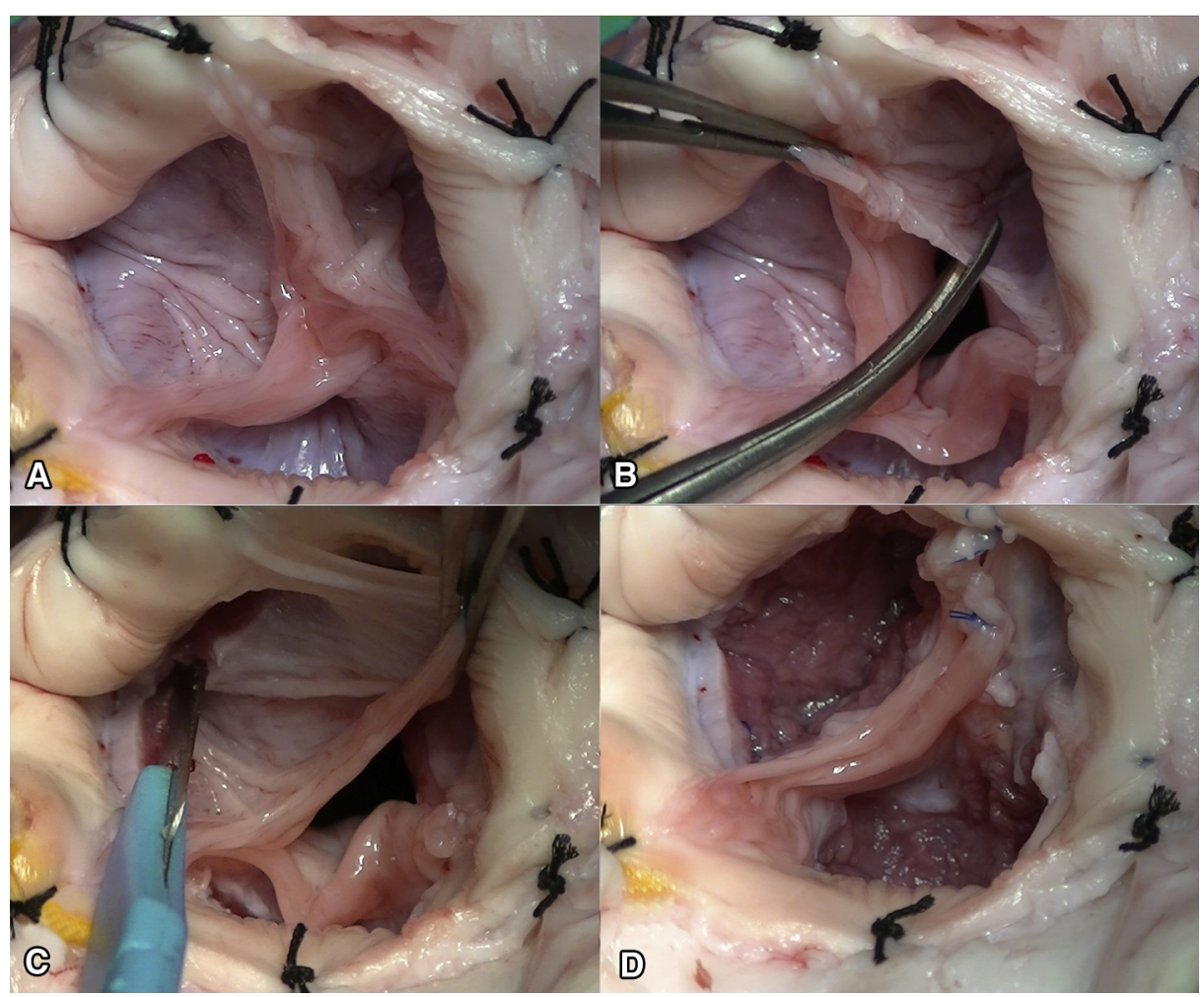

FIGURE E1. A-D, An excised bovine heart model was used to better understand the delamination plasty technique that was used to extend the PV cusp coaptation area, especially in patients with a hypoplastic PV annulus. In this model, the normal PV was exposed and examined through a longitudinal incision in the pulmonary trunk. After excision of 1 cusp of the tricuspid PV (creating a gap in coaptation mimicking the gap after PV balloon dilation in patients with a very hypoplastic PV annulus), a delamination plasty was performed on the other 2 cusps, thus extending their coaptation surface. Both cusps were then extended with triangles of biological tissue substitute and resuspended from the sinotubular junction, resulting in complete coverage of the PV annular area, simulating a bicuspid PV. A, Normal tricuspid PV; (B) removal of 1 PV cusp; (C) PV cusp delamination and leaflet extension, and (D) functionally bicuspid PV.
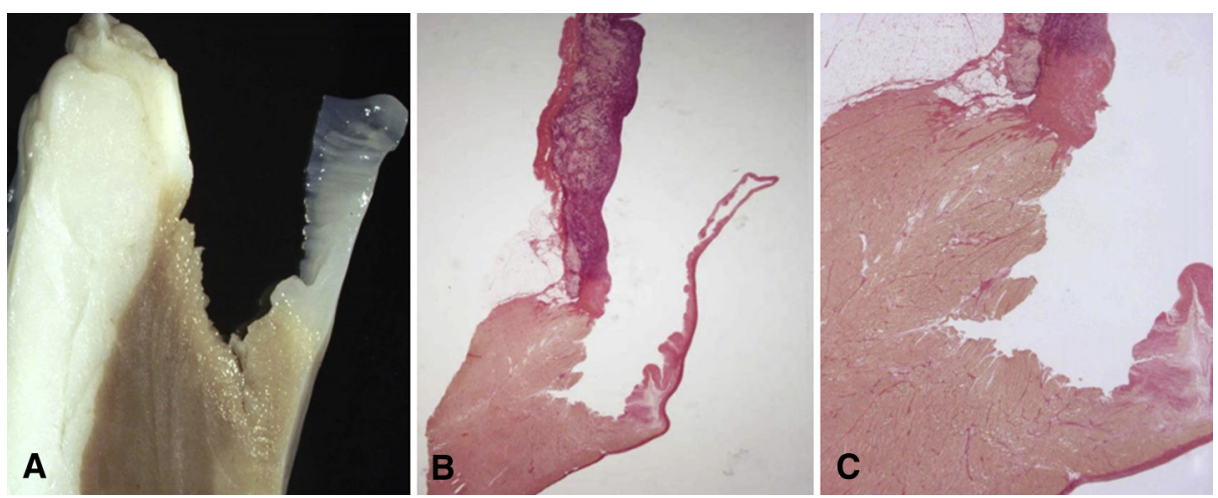

FIGURE E2. A, Anatomic view of the bovine valve after PV delamination, showing the cutting edge of the ventricular myocardium at the base of the pulmonary sinus with enlargement of the leaflet produced by the ventricular myocardium; (B) histologic view of the same specimen with delaminated fibrous leaflet, annulus, and sinus (magnification $\times 1$, elastic fiber Van Gieson staining); (C) close-up showing the delaminated area (original magnification $\times 5$, elastic fiber Van Gieson staining). 